\title{
Monitoring of platinum surface contamination in seven Dutch hospital pharmacies using inductively coupled plasma mass spectrometry
}

\author{
E. E. M. Brouwers • A. D. R. Huitema • E. N. Bakker • \\ J. W. Douma · K. J. M. Schimmel · G. van Weringh • \\ P. J. de Wolf · J. H. M. Schellens · J. H. Beijnen
}

Received: 12 September 2006 / Accepted: 1 March 2007 / Published online: 22 March 2007

(C) Springer-Verlag 2007

\begin{abstract}
Objective: To develop, validate, and apply a method for the determination of platinum contamination, originating from cisplatinum, oxaliplatinum, and carboplatinum.

Methods: Inductively coupled plasma mass spectrometry (ICP-MS) was used to determine platinum in wipe samples. The sampling procedure and the analytical conditions were optimised and the assay was validated. The method was applied to measure surface contamination in seven Dutch hospital pharmacies.

Results: The developed method allowed reproducible quantification of $0.50 \mathrm{ng} \mathrm{l}^{-1}$ platinum ( $5 \mathrm{pg} /$ wipe sample). Recoveries for stainless steel and linoleum surfaces ranged between 50.4 and $81.4 \%$ for the different platinum compounds tested. Platinum contamination was reported in $88 \%$ of the wipe samples. Although a substantial variation in surface contamination of the pharmacies was noticed, in most pharmacies, the laminar-airflow (LAF) hoods, the
\end{abstract}

E. E. M. Brouwers $(\bowtie) \cdot$ A. D. R. Huitema $\cdot$ J. H. Beijnen

Department of Pharmacy and Pharmacology,

Slotervaart Hospital/The Netherlands Cancer Institute,

Louwesweg 6, 1066 EC Amsterdam, The Netherlands

e-mail: Elke.Brouwers@slz.nl

\section{E. N. Bakker}

Department of Clinical Pharmacology and Pharmacy, Free University Medical Centre, de Boelelaan 1117, 1007 MB Amsterdam, The Netherlands

J. W. Douma

Department of Pharmacy, University Medical Centre,

Heidelberglaan 100, 3584 CX Utrecht, The Netherlands

K. J. M. Schimmel

Department of Clinical Pharmacy and Toxicology,

Leiden University Medical Centre, Albinusdreef 2,

2300 RC Leiden, The Netherlands floor in front of the LAF hoods, door handles, and handles of service hatches showed positive results. This demonstrates that contamination is spread throughout the preparation rooms.

Conclusion: We developed and validated an ultra sensitive and reliable ICP-MS method for the determination of platinum in surface samples. Surface contamination with platinum was observed in all hospital pharmacies sampled. The interpretation of these results is, however, complicated.

Keywords ICP-MS · Platinum · Validation ·

Hospital pharmacies $\cdot$ Surface contamination

\section{Introduction}

Cytotoxic drugs are widely used for the treatment of cancer. Occupational exposure to these drugs has been recog-

\author{
G. van Weringh \\ Department of Pharmacy, Sint Lucas Andreas Hospital, \\ Jan Tooropstraat 164, 1061 AE Amsterdam, The Netherlands \\ P. J. de Wolf \\ Hospital Pharmacy of Haarlem, Boerhaavelaan 24, \\ 2035 RC Haarlem, The Netherlands \\ J. H. M. Schellens $\cdot$ J. H. Beijnen \\ Department of Biomedical Analysis, \\ Faculty of Pharmaceutical Sciences, Utrecht University, \\ P.O. Box 80082, 3508 TB Utrecht, The Netherlands \\ J. H. M. Schellens $\cdot$ J. H. Beijnen \\ Department of Medical Oncology, Antoni van Leeuwenhoek \\ Hospital/The Netherlands Cancer Institute, Plesmanlaan 121, \\ 1066 CX Amsterdam, The Netherlands
}


nised as a potential health hazard since 1970s (Donner 1978; Falck et al. 1979). Because cytotoxic drugs can affect the DNA, RNA, or protein synthesis, many of these drugs are classified as being carcinogenic, mutagenic, or teratogenic to humans (International Agency for Research on Cancer (IARC) 1997). Skin contact with cytotoxic drugs, due to contamination of the work area or contamination of packaging material, seems to play an important role in the uptake of these drugs by hospital personnel (Fransman et al. 2004; Sessink et al. 1994). Therefore, strict health and safety rules have been established and applied for the handling of these agents. Evidently, the potential health risks for persons manipulating cytotoxic drugs, such as pharmacists, pharmacy technicians, nurses, and cleaners, however, still are a concern. This concern is consolidated by a number of recent publications demonstrating workplace contamination (Crauste-Manciet et al. 2005; Hedmer et al. 2005; Leboucher et al. 2002; Mason et al. 2005; Schmaus et al. 2002; Zeedijk et al. 2005; Ziegler et al. 2002) and contamination of packaging of cytotoxic drugs (Connor et al. 2005; Hedmer et al. 2005; Mason et al. 2003; Nygren et al. 2002). Moreover, detection of cytotoxic agents in urine (Ensslin et al. 1994a, b, 1997; Minoia et al. 1998; Pethran et al. 2003; Schreiber et al. 2003; Sessink et al. 1994; Turci et al. 2002) and blood (Nygren and Lundgren 1997) of personnel who were involved in preparation or administration has been reported with increasing frequency.

The relationship between prolonged exposure to small quantities of cytotoxic drugs and harmful effects is difficult to establish. Based on current scientific knowledge, it is impossible to set a level of exposure that, beyond doubt, will not cause adverse effects. Because no regulations on the maximal acceptable amount of contamination for these drugs have been set so far, hospitals should aim for the lowest contamination as is reasonably achievable. Monitoring of contamination, therefore, is essential. This can aid in the identification of the main exposure routes and in assessing the effectiveness of cleaning and working procedures. Evaluation of environmental contamination will, moreover, lead to an increase of the consciousness among personnel, concerning the handling of the chemotherapeutic agents. This can lead to an improvement of and the compliance to working and cleaning procedures. Wipe sampling is a common method to monitor surfaces for the presence of cytotoxic drugs. Hence, sensitive and validated methods are indispensable to be able to detect the relatively low quantities of drug present on surfaces.

Platinum coordination complexes, such as cisplatinum, oxaliplatinum, and carboplatinum play a major role in the treatment of a variety of tumours. As a result, large amounts of these agents are processed in hospital pharmacies.
Several wipe sample methods for platinum containing drugs have been used in earlier studies and platinum was detected as a surface contaminant in many of the workplaces (Leboucher et al. 2002; Mason et al. 2005; Schmaus et al. 2002; Ziegler et al. 2002) or drug vials (Connor et al. 2005; Nygren et al. 2002) investigated. A description of the validation of the analytical methods, however, has been scarce. Validation results were mentioned briefly for the method of Ziegler et al. (2002), using electro thermal vaporisation coupled to inductively coupled plasma mass spectrometry (ICP-MS). Raghavan et al. (2000) described the validation of a high-performance liquid chromatography method for the determination of cisplatinum in cleaning validation samples. The limit of quantification of this method, was $500 \mathrm{ng} \mathrm{l}^{-1}$, which is high compared to the limits achievable with for example ICP-MS or voltammetry. Schmaus et al. (2002) reported the validation of a voltammetric method with a limit of quantification of $40 \mathrm{pg}$ of platinum per sample.

In the present study, we describe the development and validation of an ICP-MS method for the evaluation of surface contamination by platinum originating from cisplatinum, oxaliplatinum, and carboplatinum. ICP-MS assures an ultra high sensitivity and specificity and requires relatively simple sample pre-treatment procedures. The validated method has been applied to measure surface contamination in seven Dutch hospital pharmacies.

\section{Experimental}

\section{Chemicals}

Cisplatinum and carboplatinum reference standards were purchased from Calbiochem (San Diego, CA, USA). Oxaliplatinum was obtained from Sigma-Aldrich (St Louis, MO, USA). Chloroplatinic acid, containing $1,000 \mathrm{mg} \mathrm{l}^{-1}$ platinum in $3.3 \% \mathrm{HCl}$, used for preparation of calibration solutions, was obtained from Inorganic Ventures/IV Labs (Lakewood, NJ, USA). Iridium chloride, containing $1,000 \mathrm{mg}^{-1}$ iridium in $3.3 \% \mathrm{HCl}$, used for internal standardisation, was also purchased from Inorganic Ventures/IV Labs. Nitric acid $\left(\mathrm{HNO}_{3}\right) 70 \%$ and hydrochloric acid $(\mathrm{HCl}) 35 \%$ Ultrex II ultrapure reagents were obtained from Mallinckrodt Baker (Philipsburg, NJ, USA). Water used for the ICP-MS analysis was sterile water for irrigation (Aqua B. Braun Medical, Melsungen, Germany). Ethanol $80 \%$ was purchased from Fresenius Kabi (Den Bosch, The Netherlands). A multi-element solution containing $10 \mathrm{mg} \mathrm{l}^{-1}$ of $\mathrm{Ba}, \mathrm{Be}$, $\mathrm{Ce}, \mathrm{Co}, \mathrm{In}, \mathrm{Mg}, \mathrm{Pb}$, Th, Tl (VAR-TS-MS) was purchased from Inorganic Ventures/IV Labs. Hoek Loos (Schiedam, The Netherlands) provided argon gas (4.6) with $99.996 \%$ purity. 
Instrumentation

Analyses were performed on an ICP-quadrupole-MS (Varian 810-MS) equipped with a $90^{\circ}$ reflecting ion mirror (Varian, Mulgrave, Victoria, Australia). The sample introduction system consisted of a Micromist glass low flow nebuliser (sample uptake $0.4 \mathrm{ml} \mathrm{min}^{-1}$ ), a peltier-cooled $\left(4^{\circ} \mathrm{C}\right)$ double pass glass spray chamber and a quartz torch. The spray chamber was cooled to reduce the vapour loading on the plasma, increasing the available energy for atomisation and ionisation of the elements of interest. Sample transport from the SPS-3 autosampler (Varian) to the nebuliser was performed using a peristaltic pump (WatsonMarlow Alitea, Stockholm, Sweden). The instrument was cooled by using a Kühlmobil 142 VD (Van der Heijden, Dörentrup, Germany). Data were acquired and processed using the ICP-MS Expert Software version 1.1 b49 (Varian). Further data handling was performed using Excel 2000 (Microsoft, Redmond, WA, USA). All measurements were carried out in a dedicated temperature-controlled, positively pressurised environment in order to maintain optimum instrument performance and minimise exogenous contamination. All solutions were prepared using pipettes (Falcon, Becton Dickinson Labware, Franklin Lakes, NJ, USA) and polypropylene tubes $10 \mathrm{ml}$ (Plastiques-Gosselin, Hazebrouck Cedex, France) and $30 \mathrm{ml}$ (Sarstedt AG\&Co, Nümbrecht, Germany). Filters (Minisart) used for filtration of wipe samples were obtained from Sartorius (Hannover, Germany). Prior to method development, tubes were checked thoroughly for platinum, iridium, and hafnium contamination and appeared to be suitable for platinum analyses.

\section{Determination of platinum by ICP-MS}

To optimise the ICP-MS signal for the high masses and to reduce the formation of oxides, a solution containing $1,000 \mathrm{ng}^{-1}$ of $\mathrm{Th}, \mathrm{In}, \mathrm{Ce}, \mathrm{Ba}$ and Pt was used. Typically this $1,000 \mathrm{ng} \mathrm{l}^{-1}$ solution gave readings of ${ }^{115} \mathrm{In}$, $7 \times 10^{5} \mathrm{c} \mathrm{s}^{-1} ;{ }^{232} \mathrm{Th}, 1 \times 10^{6} \mathrm{c} \mathrm{s}^{-1}$ and ${ }^{194} \mathrm{Pt}, 2 \times 10^{5} \mathrm{c} \mathrm{s}^{-1}$. The production of $\mathrm{CeO}^{+}$was less than $1.0 \%$ of the total $\mathrm{Ce}^{+}$ counts. The formation of doubly charged $\mathrm{Ba}^{++}$was less than $3 \%$. Performance was checked daily.

The platinum isotope used for calculation of platinum concentrations was ${ }^{194} \mathrm{Pt}$. Iridium was used as internal standard. Detection of platinum can be subject to the interference of hafmium oxides (Lustig et al. 1997). Therefore, hafmium signals were monitored for all samples. The detection mode for all isotopes was based on peak jumping with peak dwell times of $50 \mathrm{~ms}, 25$ scans per replicate, and three replicates per sample. Quantitation was based on the mean concentration of three replicates analysed against a calibration curve using weighted linear regression analysis.
Assay development

The most suitable wipe material, desorption solvent, and wipe solvent were selected using one surface sampling and desorption procedure. This will be described below. Recovery data were assessed for the three most commonly used platinum agents; cisplatinum, oxaliplatinum, and carboplatinum. The different molecular structures and, as a result, the variable physical characteristics, might possibly lead to a variation in absorption and desorption characteristics. Therefore, we decided to evaluate all three compounds instead of choosing one reference compound.

\section{Surface sampling and desorption procedure}

Each wipe tissue was moistened with $500 \mu \mathrm{l}$ wipe solvent. In general, sampling was performed by wiping a defined surface area of $10 \mathrm{~cm} \times 10 \mathrm{~cm}$. However, for surfaces for which it was not possible to take a $10 \mathrm{~cm} \times 10 \mathrm{~cm}$ sample, the complete top of the device was sampled and the area was estimated. All wipe samples were collected with a uniform sampling procedure by wiping in three different directions (vertical, horizontal, and diagonal). Wipe samples were stored in $50 \mathrm{ml}$ disposable polypropylene flasks (Falcon, Becton Dickinson Labware, Franklin Lakes, NJ, USA) at $-20^{\circ} \mathrm{C}$ until further processing. Prior to analysis, $10 \mathrm{ml}$ of desorption solvent was added to the sample and flasks were kept in an ultrasonic bath for $60 \mathrm{~min}$. Then, samples were filtered to remove particles which could possibly obstruct the ICP-MS nebuliser, or could interfere with the analysis. Two millilitres of sample were, after addition of iridium as internal standard, introduced directly into the ICP-MS. Samples of locations which were expected to be highly contaminated, were diluted prior to analysis to prevent contamination of the sample introduction system of the ICP-MS.

\section{Wipe material}

A variety of wipe tissues are available for collecting samples of surface contaminants. These vary in type of material, surface area, and content of platinum contaminants. Three types of wipes were evaluated for this study; Kimtech Science precision wipes (Kimberley-Clark Professional, Irving, TX, USA), Whatman glass fibre filters (Schleicher\&Schuell Microscience GmbH, Dassel, Germany), and Klinion nonwoven gauzes (Medeco, Oud-Beijerland, The Netherlands). The tissues were checked for platinum contamination and for their ability to release platinum from stainless steel surfaces.

\section{Desorption solvent}

One percent $\mathrm{HNO}_{3}(\mathrm{v} / \mathrm{v}), 5 \% \mathrm{HNO}_{3}(\mathrm{v} / \mathrm{v})$, and $1 \% \mathrm{HCl}(\mathrm{v} / \mathrm{v})$ were evaluated as desorption solutions. Kimtech Science 
precision wipes were spiked with cisplatinum, oxaliplatinum, and carboplatinum and the platinum recovery was determined after desorption with $10 \mathrm{ml}$ of each solvent.

\section{Wipe solvent}

Initially, water, $1 \% \mathrm{HCl}$, and $80 \%$ ethanol were selected as wiping solutions. To investigate the capability of these solutions to effectively wipe surfaces, $100 \mathrm{~cm}^{2}$ stainless steel surfaces were spiked with cisplatinum, oxaliplatinum, and carboplatinum. These surfaces were subsequently wiped and samples were desorbed using a $1 \% \mathrm{HCl}$ solution.

\section{Validation procedures}

\section{Linearity}

For calibration, the chloroplatinic acid reference solution containing $1,000 \mathrm{mg} \mathrm{l}^{-1}$ platinum was diluted with $1 \% \mathrm{HCl}$ to obtain working solutions with concentrations ranging from 50.0 to $5.00 \times 10^{3} \mathrm{ng}^{-1}$ platinum. Working solutions were diluted with $1 \% \mathrm{HCl}$ to obtain calibration standards, ranging from 0.500 to $100 \mathrm{ng}^{-1}$ platinum. Before analysis, $15 \mu \mathrm{l}$ of iridium internal standard solution was added to $1.5 \mathrm{ml}$ of each calibration standard (final internal standard concentration $100 \mathrm{ng}^{-1}$ ). The seven non-zero calibration standards were processed and analysed in singular in three separate analytical runs. The calibrations were back-calculated from the responses. Deviations from the nominal concentration were evaluated.

\section{Recovery and precision}

Quality control (QC) samples were prepared to obtain information on the recovery and precision of the desorption method and platinum analysis. These samples were analysed in the validation runs and subsequently also during the analysis of the wipe samples of each hospital pharmacy. Therefore, stock solutions of the platinum agents in water, each containing a concentration of drug equivalent to $400 \mathrm{mg} \mathrm{l}^{-1}$ platinum, were prepared. These stock solutions were further diluted to obtain spiking solutions with concentrations ranging from 10.0 to $2.00 \times 10^{3} \mathrm{ng}^{-1}$. Tissues were spiked with these solutions serving as QC samples at the following concentration levels; $5.00 \times 10^{-3}$, $2.5 \times 10^{-2}, 0.100$, and $1.00 \mathrm{ng}$ platinum on the tissues, corresponding to $0.500,2.50,10.0$, and $100 \mathrm{ng} 1^{-1}$ platinum in the final solution. These tissues were processed as described earlier. Three replicates of each sample were analysed in three analytical runs. Recovery was expressed as a percentage of the nominal concentration. Within-run and between-run precisions were calculated by analysis of variances (ANOVA) for each test concentration using the analytical run as the grouping variable.

Two of the most important surfaces, stainless steel and linoleum, were used to obtain information on the recovery and within-run and between-run precisions of the complete sampling procedure, including both wiping and desorption. Therefore, $1.00 \mathrm{ng}$ of cisplatinum, oxaliplatinum, or carboplatinum was pipetted in triplicate on a $100 \mathrm{~cm}^{2}$ stainless steel and linoleum surface. After drying overnight, surfaces were wiped following the previously described procedure and analysed using ICP-MS. Three replicates of each sample were analysed in three analytical runs for both surfaces. Recovery was expressed as a percentage of the nominal concentration. Within-run and between-run precision were calculated by ANOVA for each test concentration using the analytical run as the grouping variable.

\section{Sensitivity}

The lower limit of quantitation (LLOQ) was defined as the concentration at which the analyte response was at least five times the response of a blank wipe sample. Besides, the LLOQ, when spiked on blank tissues, had to be determined with a precision less than $20 \%$ and the mean value should not deviate more than $20 \%$ of the actual value.

\section{Stability}

Stability of cisplatinum, oxaliplatinum, and carboplatinum spiked to tissues, at two concentration levels, was evaluated at ambient temperatures for 1 week and under storage conditions $\left(-20^{\circ} \mathrm{C}\right)$ for up to 3 weeks. From each storage condition two wipe samples were analysed. Samples were considered stable when $80-120 \%$ of the initial concentration was recovered.

Platinum determination in pharmacy facilities where no cytotoxic agents are processed

Platinum is an element that not only appears in the environment due to contamination with platinum containing cytotoxic drugs, but also due to pollution by car exhaust catalysts. As a consequence, road dust also contains platinum (Barefoot 1997). Even though, in the pharmacy facilities, precautions (use of slippers/clogs) are taken to reduce the chance of contamination of the facility, road dust contamination might occur. Because ICP-MS does not differentiate between the sources of elemental platinum, this should be taken into account when considering this technique for evaluation of environmental contamination by cytotoxic platinum agents. Therefore, two additional locations were included in this study to set a threshold below which it was not possible to address the source of the contamination. The 
first location was the laminar-airflow (LAF) hood in a clean room in which no platinum contamination was expected. The second location was a preparation unit with LAF hood of a public pharmacy.

Monitoring of surface contamination in seven Dutch hospital pharmacies

The wipe samples were taken in seven hospital pharmacies in The Netherlands. Characteristics of the facilities are shown in Table 1. The facilities were selected to provide a representation of the diversity in hospital pharmacies in The Netherlands in terms of size and amount of platinum compounds handled. The facilities of each hospital consisted of a preparation room with at least one LAF hood and a room for storage and checking of the prepared drugs and administration purposes. In each facility, samples were taken at locations that were prone to contamination. For good comparison of the results 15 standard locations (Fig. 1) were selected: (1) the middle of the bench-top of the LAF hood, (2) front edge of LAF hood, (3) floor in front of LAF hood, (4) handle of service hatch, (5) door handle, (6) waste bin top, (7) bench-top on which materials are placed in storage/ checking room, (8) floor in front of (7), (9) mouse computer, (10) handle telephone, (11) storage shelve of cisplatinum, (12) storage shelve oxaliplatinum, (13) storage shelve carboplatinum, (14) transport box, (15) handle refrigerator. Locations 1, 2, and 3 were sampled in duplicate to get an impression of the overall contamination of these locations. A new pair of gloves was used for each wipe sample. For each facility three blank samples were prepared by moistening tissue with $500 \mu \mathrm{l}$ water. All samples were stored and processed as described earlier. The storage time from sampling until work-up procedure was less than 2 weeks.

Wipe sampling was announced in each facility in advance and was performed after the daily cleaning procedure of the

Table 1 Amount of platinum agents processed and years that the facilities are in service

\begin{tabular}{|c|c|c|c|c|c|c|c|}
\hline & \multicolumn{7}{|l|}{ Site } \\
\hline & 1 & 2 & 3 & 4 & 5 & 6 & 7 \\
\hline Cisplatinum use in 2005 (in g) & 52.3 & 6.80 & 64.0 & 147 & 16.8 & 29.9 & 104 \\
\hline Oxaliplatinum use in 2005 (in g) & 47.5 & 8.65 & 44.1 & 109 & 23.4 & 98.8 & 62.0 \\
\hline Carboplatinum use in 2005 (in g) & 256 & 48.2 & 124 & 635 & 56.5 & 223 & 217 \\
\hline $\begin{array}{l}\text { Total amount of platinum } \\
\text { processed in } 2005 \text { (in g) }\end{array}$ & 192 & 34.0 & 129 & 483 & 52.1 & 185 & 212 \\
\hline Number of years in service & 5 & 10 & 18 & 2.5 & 1.5 & 10 & 15 \\
\hline Wipe sampling frequency & $\begin{array}{l}\text { Once } \\
\text { per year }\end{array}$ & $\begin{array}{l}2005 \text { first } \\
\text { time }\end{array}$ & $\begin{array}{l}\text { Sporadic: } \\
\text { last in } 2004\end{array}$ & $\begin{array}{l}\text { Once } \\
\text { per year }\end{array}$ & $\begin{array}{l}\text { Once } \\
\text { per year }\end{array}$ & $\begin{array}{l}\text { Once } \\
\text { per year }\end{array}$ & $\begin{array}{l}\text { Twice } \\
\text { per year }\end{array}$ \\
\hline
\end{tabular}

Fig. 1 Sample locations in pharmacy facilities

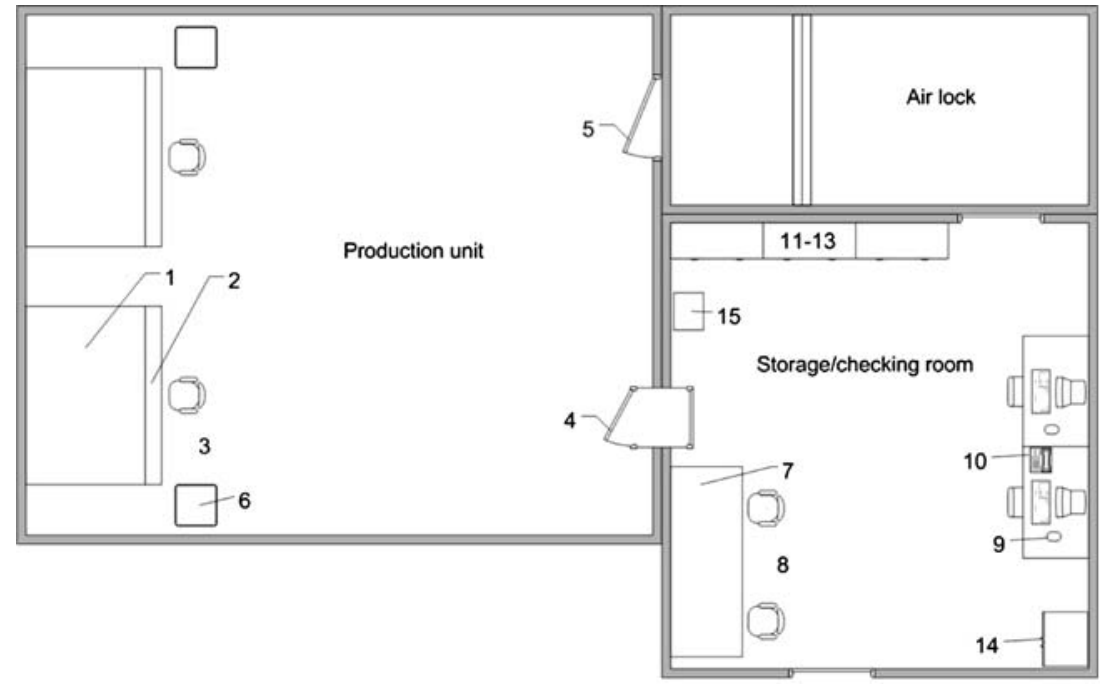

(1) the middle of the bench-top of the LAF hood, (2) front edge of LAF hood, (3) floor in front of LAF hood, (4) handle of service hatch, (5) door handle, (6) waste bin top, (7) bench-top on which materials are placed in storage/checking room, (8) floor in front of (7), (9) mouse computer, (10) handle telephone, (11) storage shelve of cisplatin, (12) storage shelve oxaliplatin, (13) storage shelve carboplatin, (14) transport box, (15) handle refrigerator 
LAF hoods, but before the daily cleaning procedure of the rest of the facility. Wipe sampling in all the facilities was performed by the same person.

\section{Results}

Assay development

\section{Wipe material}

As a result of high platinum backgrounds (10-20 pg platinum per filter depending on the batch analysed), Whatman glass fibre filters were found to be not suitable for platinum wipe sampling. Kimtech Science precision wipes and Klinion non-woven gauzes did not show platinum contamination. However, Kimtech Science precision wipes showed better recoveries of platinum compared to Klinion nonwoven gauzes and consequently Kimtech Science precision wipes appeared to be the best choice.

\section{Desorption solvent}

The most effective desorption of platinum from the wipe materials was achieved by $1 \% \mathrm{HCl}(94-99 \%)$. As a result $1 \% \mathrm{HCl}$ was selected as the desorption solution of choice.

\section{Wipe solvent}

Recoveries were inadequate for $80 \%$ ethanol $(<40 \%$ for all three compounds) and acceptable for water (50-77\%) and $1 \% \mathrm{HCl}(63-78 \%)$. Because $1 \% \mathrm{HCl}$ appeared to be corrosive for some types of stainless steel, water was selected as wipe solution.

Validation procedures

\section{Linearity}

The calibration curve was best described by linear regression, using $1 /$ (sd of triplicate sample reading) as weight-fac- tor, to avoid bias in favour of samples with high standard deviations. Deviations from the nominal concentration were between -10.0 and 10.2 for all concentration levels. Relative standard deviations for the calibration samples were up to $7.84 \%$. Correlation coefficients were higher than 0.99999 .

\section{Recovery and precision}

Within-run and between-run precision data for spiked tissues, which served as QCs are summarised in Table 2. Precision data showed that, for all QC concentration levels, the reproducibility of the desorption procedure and platinum analysis was excellent. Recoveries for cisplatinum, oxaliplatinum, and carboplatinum were between 86.7 and $103 \%$ for all concentration levels. These results indicated sufficient recovery.

For recovery and within-run and between-run precision data from the spiked stainless steel and linoleum surfaces see, respectively, Tables 3 and 4. Precision data showed that the reproducibility of the method, including the wiping procedure was good. Recoveries from the spiked stainless steel surface were $50.4 \%$ for cisplatinum, $73.8 \%$ for oxaliplatinum, and $77.2 \%$ for carboplatinum (Table 3). Recoveries for the linoleum surface were, respectively, 76.8, 77.9, and $81.4 \%$ (Table 4 ).

\section{Sensitivity}

The LLOQ of the assay was set at a platinum concentration of $0.5 \mathrm{ng} \mathrm{l}^{-1}$ in $1 \% \mathrm{HCl}$, corresponding to $5 \mathrm{pg}$ per wipe sample or $0.05 \mathrm{pg} \mathrm{cm}^{-2}$ taking into account a surface of $10 \mathrm{~cm} \times 10 \mathrm{~cm}$. Signal to noise ratios at the LLOQ level exceeded 5 during all the experiments, which was in accordance with the requirement. The acceptance criteria, that the LLOQ was determined with a precision less than $20 \%$ and that the mean value should deviate no more than $20 \%$ from the actual value, were met for all three compounds (Table 2).

\section{Stability}

Stability has now been established up to 3 weeks, but further testing is still ongoing. Sample storage at room

Table 2 Within and between-run precision data for quality control samples

\begin{tabular}{|c|c|c|c|c|c|c|c|}
\hline \multirow{2}{*}{$\begin{array}{l}\text { Amount of platinum } \\
\text { spiked to tissue (in ng) }\end{array}$} & \multirow{2}{*}{$\begin{array}{l}\text { Final platinum } \\
\text { concentration (in ng } 1^{-1} \text { ) }\end{array}$} & \multicolumn{2}{|l|}{ Cisplatinum } & \multicolumn{2}{|c|}{ Oxaliplatinum } & \multicolumn{2}{|c|}{ Carboplatinum } \\
\hline & & Within-run & Between-run & Within-run & Between-run & Within-run & Between-run \\
\hline $5.00 \times 10^{-3}$ & 0.500 & 7.75 & a & 8.53 & a & 8.01 & 8.75 \\
\hline $2.50 \times 10^{-2}$ & 2.50 & 4.10 & 4.05 & 1.66 & 1.15 & 2.39 & $\mathrm{a}$ \\
\hline 0.100 & 10.0 & 1.35 & 7.44 & 1.75 & 1.27 & 2.86 & 2.50 \\
\hline 1.00 & 100 & 1.07 & 7.79 & 1.63 & a & 0.84 & 1.96 \\
\hline
\end{tabular}

${ }^{a}$ No statistically significant additional value was observed as a result of performing the assay in different runs (mean square within runs is greater than mean square between runs) 
Table 3 Recovery of 1.00 ng platinum from a stainless steel surface

\begin{tabular}{llll}
\hline & Cisplatinum & Oxaliplatinum & Carboplatinum \\
\hline Mean recovery (\%) & 50.4 & 73.8 & 77.2 \\
$\begin{array}{l}\text { Within-run } \\
\text { precision (in \%) }\end{array}$ & 2.21 & 4.63 & 2.53 \\
$\begin{array}{c}\text { Between-run } \\
\text { precision (in \%) }\end{array}$ & 3.36 & a & a \\
$\begin{array}{l}\text { Number of days } \\
\text { Number of samples } \\
\text { per day }\end{array}$ & 3 & 3 & 3 \\
\hline
\end{tabular}

$\overline{{ }^{a} \text { No statistically significant additional value was observed as a result }}$ of performing the assay in different runs (mean square within runs is greater than mean square between runs)

Table 4 Recovery of 1.00 ng platinum from a linoneum surface

\begin{tabular}{llll}
\hline & Cisplatinum & Oxaliplatinum & Carboplatinum \\
\hline Mean recovery (\%) & 76.8 & 77.9 & 81.4 \\
$\begin{array}{l}\text { Within-run } \\
\text { precision (in \%) }\end{array}$ & 3.62 & 2.12 & 3.35 \\
$\begin{array}{l}\text { Between-run } \\
\text { precision (in \%) }\end{array}$ & 12.2 & 5.41 & 6.82 \\
$\quad$ Number of days & 3 & 3 & 3 \\
$\quad \begin{array}{l}\text { Number of samples } \\
\text { per day }\end{array}$ & 3 & 3 & 3 \\
\hline
\end{tabular}

temperature for 1 week was not possible. Tissues which were spiked with cisplatinum showed a decrease in platinum levels of $30 \%$ after 1 week. Oxaliplatinum and carboplatinum spiked tissues did not reduce under these conditions. Sample storage at $-20^{\circ} \mathrm{C}$ was possible for at least 3 weeks. Platinum concentrations of cisplatinum spiked tissues were decreasing more obvious with time than oxaliplatinum and carboplatinum spiked tissues. However, no decrease of more than $20 \%$ of the initial concentration was observed after 3 weeks at $-20^{\circ} \mathrm{C}$.

Platinum determination in pharmacy facilities where no cytotoxic agents are processed

No platinum was detected in wipe samples from the LAF hood of the public pharmacy. Platinum levels of the LAF hood in the clean room and the floor in the public pharmacy ranged between 0.430 and $0.922 \mathrm{ng} \mathrm{l}^{-1}$ (or 0.0430-0.0922 $\mathrm{pg} \mathrm{cm}{ }^{-2}$ ). Therefore, it was recommended to set a threshold of $1.00 \mathrm{ng} \mathrm{l}^{-1}$ platinum $\left(0.100 \mathrm{pg} \mathrm{cm}^{-2}\right.$ when wiping a surface of $100 \mathrm{~cm}^{2}$ ), below which it was not possible to address the source of the contamination. All surfaces in the preparation units with platinum levels above this threshold were considered as being contaminated by platinum containing drugs.
Monitoring surface contamination in seven Dutch hospital pharmacies

In February 2006, wipe samples were collected from seven Dutch hospital pharmacies with centralised units dedicated to the preparation of intravenous mixtures of cytotoxic drugs. The amount of platinum which was processed in these facilities ranged from 34.0 to $483 \mathrm{~g}$ per year (Table 1). Surface contamination of all sample locations is depicted in Table 5 in $\mathrm{pg} \mathrm{cm}^{-2}$. It is important to consider that recoveries of the samples, as assessed in the validation study, deviate from $100 \%$ dependent on the type of surface sampled and on the type of compounds present on the surface. Therefore, results depicted in Table 5 represent $\geq 50.4 \%$ of the actual contamination present on the surface.

Platinum was detected in $94 \%$ of the wipe samples and $88 \%$ of the samples contained levels above the threshold set. Six of the 126 samples showed raised hafmium signals which, considering a maximum oxide formation of $1 \%$, might have accounted for up to $20 \%$ of the platinum signals of these samples. None of blank samples prepared for each facility by moistening tissues with wipe solvent, contained levels of platinum exceeding $20 \%$ of the LLOQ standard. The variation in the level of contamination between pharmacies was high. Pharmacies of site 1 and 5 showed overall low platinum contaminations. For these sites, respectively 33 and $39 \%$ did not contain platinum levels above the threshold set. Platinum levels detected at pharmacy 3 were relatively low as well, although the wipes taken from the floor were high at this site. These high values were, most probably, the result of a calamity in 2005 with a cisplatinum infusion mixture, which was spilled on the floor. Most locations wiped at the hospital pharmacies of site 2, 4, 6, and 7 showed high contaminations. Only one sample from these sites did not contain any detectable platinum. The high contamination of site 2 seemed to run counter to the quantities of drugs handled, because in this pharmacy relatively low amounts of platinum were processed. This site, however, was occasionally used, for preparation of larger amounts of cytotoxic drugs to serve another hospital. Therefore, the amount of drugs processed in 2005, was not fully representative for the amount of drugs processed in the 10 years that this site was in use. Site 4 showed the highest contamination, which paralleled the relative amount of drug handled in this unit.

As expected, platinum was found in most wipe samples taken from the middle of the LAF hood bench. Notable was that, in general, wipe samples of the front edge of the LAF hood were more contaminated than samples taken from the bench-top of the LAF hood. Furthermore, floor samples usually contained the highest platinum levels. Other locations showing substantial contamination were storage shelves, door handles, and handles of service hatches. Duplicate 
Table 5 Platinum contamination in seven Dutch hospital pharmacies

\begin{tabular}{|c|c|c|c|c|c|c|c|c|}
\hline \multirow[t]{3}{*}{ S.no. } & \multirow[t]{3}{*}{ Sampled surface } & \multicolumn{7}{|c|}{ Platinum contamination (in $\mathrm{pg} \mathrm{cm}^{-2}$ ) } \\
\hline & & \multicolumn{7}{|l|}{ Site } \\
\hline & & 1 & 2 & 3 & 4 & 5 & 6 & 7 \\
\hline \multirow[t]{2}{*}{1} & Middle of bench LAF hood & 0.22 & 180 & 0.54 & 32.7 & 0.360 & 7.22 & 2.94 \\
\hline & Duplicate of 1 & 0.189 & 124 & 0.645 & 18.7 & 0.328 & 8.22 & 2.28 \\
\hline \multirow[t]{2}{*}{2} & Front edge of LAF hood & $-^{\mathrm{a}}$ & 356 & 3.32 & 99.5 & 0.133 & 28.2 & 5.12 \\
\hline & Duplicate of 2 & $-{ }^{\mathrm{a}}$ & 268 & 8.34 & 180 & $-^{\mathrm{a}}$ & 37.0 & 5.19 \\
\hline \multirow[t]{2}{*}{3} & Floor in front of LAF hood & 3.14 & 173 & 824 & 1,107 & 0.228 & 2.48 & 21.7 \\
\hline & Duplicate of 3 & 3.20 & 232 & 728 & 2,211 & 0.186 & 1.91 & 12.5 \\
\hline 4 & Handle of service hatch & $-^{\mathrm{a}}$ & 22.7 & $-{ }^{\mathrm{a}}$ & 2,055 & $-^{\mathrm{a}}$ & 1.96 & 11.8 \\
\hline 5 & Door handle & $-^{\mathrm{a}}$ & 3.17 & $-{ }^{\mathrm{a}}$ & 16.8 & $-{ }^{\mathrm{a}}$ & 21.4 & 16.1 \\
\hline 6 & Waste bin top & $-{ }^{\mathrm{a}}$ & 1.02 & 0.392 & 10.1 & $--^{\mathrm{a}}$ & 7.38 & $0.098^{\mathrm{c}}$ \\
\hline 7 & Bench-top on which materials are placed & 0.829 & 0.949 & 0.298 & 90.6 & 0.202 & 0.375 & 63.4 \\
\hline 8 & Floor in front of bench & $0.105^{\mathrm{c}}$ & 19.7 & 58.9 & 38.1 & $-^{\mathrm{a}}$ & $0.311^{\mathrm{c}}$ & 11.9 \\
\hline 9 & Mouse computer & 0.252 & 0.816 & 1.34 & 10.2 & $-{ }^{\mathrm{b}}$ & 0.758 & 5.41 \\
\hline 10 & Handle telephone & $-^{\mathrm{a}}$ & 3.22 & 0.59 & 12.1 & $-{ }^{\mathrm{a}}$ & 3.06 & 5.12 \\
\hline 11 & Storage shelve cisplatinum & $0.176^{\mathrm{c}}$ & 1.14 & $0.157^{\mathrm{c}}$ & 4.76 & 0.536 & 4.04 & 336 \\
\hline 12 & Storage shelve oxaliplatinum & 0.368 & 0.916 & $0.141^{\mathrm{c}}$ & 4.10 & 82.7 & 1.15 & 2.21 \\
\hline 13 & Storage shelve carboplatinum & 3.25 & 1.53 & 0.147 & 3.13 & 0.186 & 0.989 & 5,760 \\
\hline 14 & Transport box & 74.5 & $-^{\mathrm{a}}$ & 0.285 & 4.44 & $-^{\mathrm{a}}$ & 0.828 & $-^{\mathrm{b}}$ \\
\hline 15 & Handle refrigerator & 0.452 & 26.3 & 1.46 & 36.0 & 0.948 & 1.42 & 5.71 \\
\hline
\end{tabular}

samples of locations 1, 2, and 3 showed similar results, indicating a homogeneous distribution over de surface area.

The number of years that the seven units were in use, did not parallel contamination levels and the amount of drug handled in 2005, overall, did not predict the level of contamination either.

\section{Discussion}

The presence of cytotoxic drug contamination in hospital pharmacies is recognized as a potential health risk. Therefore, it is important to monitor this contamination. Because platinum coordination complexes belong to the most extensively used anticancer agents, it is relevant to focus on the occupational exposure of these drugs. The rationale for evaluation of platinum contamination is also illustrated by several studies showing increased levels of platinum in blood (Nygren and Lundgren 1997) and urine (Ensslin et al. 1994a, 1997; Nygren and Lundgren 1997; Pethran et al. 2003; Schreiber et al. 2003; Turci et al. 2002) of hospital personnel working with these agents.

To be able to accurately assess the platinum contamination originating from cisplatinum, oxaliplatinum, and carboplatinum at different locations, we developed and validated a wipe sampling method. ICP-MS was used for quantification of platinum, because this technique assures a high sensitivity and relative simple sample pre-treatment. The sensitivity of the method was excellent. The LLOQ was set at a platinum concentration of $0.5 \mathrm{ng} \mathrm{l}^{-1}$, corresponding to $5 \mathrm{pg}$ per sample or $0.05 \mathrm{pg} \mathrm{cm}^{-2}$ when wiping a surface of $100 \mathrm{~cm}^{2}$. To our best knowledge, the method described here is 2-300 times more sensitive than other methods described for determination of platinum in wipe samples (Connor et al. 2005; Mason et al. 2003, 2005; Raghavan et al. 2000; Schmaus et al. 2002; Ziegler et al. 2002).

Sample pre-treatment only involved surface sampling, desorption, and filtration. After filtration, samples could be analysed immediately. During method development it was shown that, in addition to tissue material and desorption solvent, also the wipe solvent affected the recovery to a considerable extent. This was in contrast with results described by Turci et al. (2003), who mentioned that the type of wipe solvent would not influence the recovery, since contaminants would be wept away from the surfaces independent of the composition or the $\mathrm{pH}$ of the solution itself. Best recoveries were achieved by wiping with 
Kimtech Science precision wipes moistened with $500 \mu \mathrm{l}$ water and subsequent desorption with $1 \% \mathrm{HCl}$.

Validation of the method was performed for the three, in oncology most prominently used platinum agents, cisplatinum, oxaliplatinum, and carboplatinum. We decided not to choose one reference compound, because the different molecular structures of the platinum agents and, as a result, the variable physical characteristics, might possibly lead to a variation in absorption and desorption characteristics. Excellent reproducibility (imprecision up to $8.75 \%$ ) and recoveries (86.7-103\%) were demonstrated with spiked tissues, for all concentration levels and compounds. Up to $13.3 \%$ of the initial amount of platinum added to the tissues was not recovered after desorption and analysis. This could be due to variation in analysis, as well as loss due to adsorption to the tissues. Recoveries from the spiked stainless steel surface were $50.4 \%$ for cisplatinum, $73.8 \%$ for oxaliplatinum, and $77.2 \%$ for carboplatinum. Recoveries, for the three compounds, from the linoleum surface were, respectively, $76.8,77.9$, and $81.4 \%$. These results showed that for stainless steel, depending on the compound analysed, up to $49.6 \%$ of the initial amount of platinum spiked to the surface was lost. This was, for the greater part, caused by the inability of the wipe procedure to remove all the added platinum and, for a minor part, by the variation in analysis and loss due to adsorption to the tissues. The lower recovery that was observed for cisplatinum, is, most probably, a consequence of its superior reactivity compared to oxaliplatinum and carboplatinum. This might lead to a stronger binding affinity of cisplatinum to materials and surfaces. For linoleum up to $23.2 \%$ of the initial amount of platinum spiked to the surface was not recovered. For this surface, recoveries were similar for all compounds.

To evaluate the stability of spiked samples, recoveries were assessed after storage at room temperature and $-20^{\circ} \mathrm{C}$. Storage of spiked tissues at $-20^{\circ} \mathrm{C}$ for at least 3 weeks was possible. However, storage of tissues spiked with cisplatinum for 1 week at room temperature led to considerable decrease in platinum levels. Even though platinum concentrations from oxaliplatinum and carboplatinum spiked tissues did not reduce under these conditions, storage at room temperature was not recommended, also because the source of elemental platinum is not known in wipe samples performed in pharmacies. Differences in recovery of the cisplatinum and the oxaliplatinum and carboplatinum spiked samples, again, could be explained by the higher reactivity of cisplatinum.

For a correct interpretation of surface sampling results, it is relevant to take into account that platinum is an element that not only appears in the environment due to contamination with platinum containing cytotoxic drugs, but also due to pollution by car exhaust catalysts. By wipe sampling two locations where no cytotoxic drugs were handled, we, therefore, determined that below a threshold of $1.00 \mathrm{ng} \mathrm{l}^{-1}$ platinum $\left(0.100 \mathrm{pg} \mathrm{cm}^{-2}\right.$ when wiping a surface of $100 \mathrm{~cm}^{2}$ ), it was not possible to address the source of contamination. All surfaces in the preparation units with platinum levels above the threshold were considered as being contaminated by platinum containing drugs.

Taking this threshold into consideration, platinum contamination was reported in $88 \%$ of the samples taken in the seven Dutch hospital pharmacies. It is important to consider that recoveries of the samples, as assessed in the validation study, deviate from $100 \%$ dependent on the type of surface sampled and on the type of compounds present on the surface. Therefore, results depicted in Table 5 represent $\geq 50.4$ of the actual contamination present on the surface.

The results of this study indicate that there is substantial variation in surface contamination of the pharmacies tested and that the amount of platinum processed in the pharmacies did not always parallel the level of contamination. The number of preparations with platinum drugs was, however, not assessed and might also be related to surface contamination. This suggests that variation in the application of or compliance to cleaning and working procedures and the incidence of calamities, rather than the amount of platinum processed, caused variation in surface contamination.

In general, results reveal that the LAF hoods, the floor in front of the LAF hoods, door handles, and handles of service hatches were often contaminated. This demonstrates that contamination is often spread throughout the pharmacy. Notable was that wipe samples of the front edge of the LAF hood were more contaminated than samples from the bench-top of the LAF hood. This is thought to be due to incorrect application of working procedures or insufficient cleaning.

By taking duplicate wipe samples of the LAF hood, the front edge of the LAF hood, and the floor, we demonstrated that these locations were overall contaminated and that contamination did not appear to be spotty as was mentioned by Zeedijk et al. (2005).

We also investigated storage shelves and, in most pharmacies, considerable platinum contamination was found. These elevated levels could be a consequence of elevated levels of platinum on packaging material (Connor et al. 2005; Mason et al. 2003; Nygren et al. 2002). Contamination of packaging can lead to a spread of cytotoxic drugs to locations where the drugs are stored or processed. Therefore, it was not surprising that the storage shelves of platinum agents were contaminated. Furthermore, it was noticed that in at least one of the hospital pharmacies (at site 4), secondary packaging and caps of the vials were discarded onto the floor during preparation, most probably to prevent the packaging from interfering with preparation activities. This pharmacy indeed showed considerable contamination of the floor. 
In our study, surfaces showed platinum contamination of up to $5,760 \mathrm{pg} \mathrm{cm}^{-2}$. The results are in the same range as findings of some other studies describing surface contamination of platinum in hospital pharmacies (Leboucher et al. 2002; Schmaus et al. 2002). In the study of Leboucher et al. (2002), however, no platinum was found outside the LAF hood, which could be due to the high detection limit of the atomic absorption spectrometry method used $\left(10 \mu \mathrm{g} \mathrm{l}^{-1}\right)$. Schmaus et al. (2002) performed a study in 14 hospital pharmacies and all samples tested positive for platinum, even though the LLOQ of their method was eight times higher than of the method described here. Yet, although in our study not all samples tested positive for platinum, the highest contamination found $\left(5,760 \mathrm{pg} \mathrm{cm}^{-2}\right)$ was comparable to the highest contamination found by Schmaus et al. $\left(2,700 \mathrm{pg} \mathrm{cm}^{-2}\right)$. Mason et al. (2005) showed lower contamination levels than found in our study, despite that the amount of drug handled in these pharmacies was higher than in the pharmacies in our study.

When comparing the amounts of platinum detected on different locations in this study (up to $0.576 \mu \mathrm{g}$ per wipe sample) with the platinum content of one vial (between 6.50 and $237 \mathrm{mg}$ platinum), contamination seems to be relatively low. Furthermore, the extremely sensitive technique used in this study, leads to a high percentage of positive samples. Interpretation of these results is rather complicated. It is important to consider that the total area of the contamination is large and that pharmacy personnel are at risk to be exposed to the contamination daily. Hence, for safety precautions, it is recommended to attempt to achieve the lowest possible contamination. Environmental monitoring therefore, may be used to monitor and control contamination and thereby evaluate working and cleaning procedures, rather than to interpret potential health risks.

In general, when a minimal contamination level is desired, the results of this study demonstrate that cleaning and working procedures do not sufficiently prevent contamination in most hospitals. This could be due to an inadequate compliance of personnel to these procedures. Moreover, contamination can spread out unconsciously by hands or feet of the personnel. It is also likely that cleaning procedures as applied in the different pharmacies are not fully optimised and validated, leading to contamination due to sub-optimal cleaning. With respect to the physical properties of the different cytotoxic drugs, it is recommended to consider cleaning techniques appropriate for specific agents. As was shown in this study for platinum, for instance, $80 \%$ ethanol did not effectively remove platinum from a stainless steel surface. Although water gave better recoveries for platinum, it was not capable of removing all of the added platinum from the stainless steel surface. This illustrates the importance to evaluate several cleaning procedures for the different cytotoxic agents handled and to optimise a procedure which does remove all drugs with acceptable recoveries.

In conclusion we developed and validated an ultra sensitive and reliable ICP-MS method for the determination of platinum in surface samples. This method was successfully applied in the evaluation of platinum contamination in the preparation units of seven Dutch hospital pharmacies. It was demonstrated that pharmacy personnel is at risk to be exposed to platinum, despite the use of cleaning and safety procedures. As long as the consequences of long-term exposure are not known, the aim should be to achieve a contamination levels as low as possible. This study, therefore, highlights the need to further evaluate cleaning and safety procedures. Wipe sampling can be applied to quantify improvements made through changes in procedures.

Acknowledgement We gratefully acknowledge the financial support by The Netherlands Organisation for Health Research and Development, ZonMw (OND1307436).

\section{References}

Barefoot RR (1997) Determination of platinum at trace levels in environmental and biological samples. Environ Sci Technol 31:309-314

Connor TH, Sessink PJ, Harrison BR, Pretty JR, Peters BG, Alfaro RM, Bilos A, Beckmann G, Bing MR, Anderson LM, Dechristoforo R (2005) Surface contamination of chemotherapy drug vials and evaluation of new vial-cleaning techniques: results of three studies. Am J Health Syst Pharm 62:475-484

Crauste-Manciet S, Sessink PJ, Ferrari S, Jomier JY, Brossard D (2005) Environmental contamination with cytotoxic drugs in healthcare using positive air pressure isolators. Ann Occup Hyg 49:619-628

Donner AL (1978) Possible risk of working with antineoplastic drugs in horizontal laminar flow hoods. Am J Hosp Pharm 35:900

Ensslin AS, Pethran A, Schierl R, Fruhmann G (1994a) Urinary platinum in hospital personnel occupationally exposed to platinumcontaining antineoplastic drugs. Int Arch Occup Environ Health 65:339-342

Ensslin AS, Stoll Y, Pethran A, Pfaller A, Rommelt H, Fruhmann G (1994b) Biological monitoring of cyclophosphamide and ifosfamide in urine of hospital personnel occupationally exposed to cytostatic drugs. Occup Environ Med 51:229-233

Ensslin AS, Huber R, Pethran A, Rommelt H, Schierl R, Kulka U, Fruhmann G (1997) Biological monitoring of hospital pharmacy personnel occupationally exposed to cytostatic drugs: urinary excretion and cytogenetics studies. Int Arch Occup Environ Health 70:205-208

Falck K, Grohn P, Sorsa M, Vainio H, Heinonen E, Holsti LR (1979) Mutagenicity in urine of nurses handling cytostatic drugs. Lancet 1:1250-1251

Fransman W, Vermeulen R, Kromhout H (2004) Occupational dermal exposure to cyclophosphamide in Dutch hospitals: a pilot study. Ann Occup Hyg 48:237-244

Hedmer M, Georgiadi A, Bremberg ER, Jonsson BA, Eksborg S (2005) Surface contamination of cyclophosphamide packaging and surface contamination with antineoplastic drugs in a hospital pharmacy in Sweden. Ann Occup Hyg 49:629-637

International Agency for Research on Cancer (IARC) (1997) Monographs on the evaluation of the carcinogenic risks of chemicals to 
humans: overall evaluations of carcinogenicity. Updation of IARC monographs. vols 1-42. Lyon, France. http://www iarc fr

Leboucher G, Serratrice F, Bertholle V, Thore L, Bost M (2002) [Evaluation of platinum contamination of a hazardous drug preparation area in a hospital pharmacy]. Bull Cancer 89:949-955

Lustig L, Zang S, Michalke B, Schramel P, Beck W (1997) Platinum determination in nutrient plants by inductively coupled plasma mass spectrometry with special respect to the hafnium oxide interference. Fresenius J Anal Chem 357:1157-1163

Mason HJ, Morton J, Garfitt SJ, Iqbal S, Jones K (2003) Cytotoxic drug contamination on the outside of vials delivered to a hospital pharmacy. Ann Occup Hyg 47:681-685

Mason HJ, Blair S, Sams C, Jones K, Garfitt SJ, Cuschieri MJ, Baxter PJ (2005) Exposure to antineoplastic drugs in two UK hospital pharmacy units. Ann Occup Hyg 49:603-610

Minoia C, Turci R, Sottani C, Schiavi A, Perbellini L, Angeleri S, Draicchio F, Apostoli P (1998) Application of high performance liquid chromatography/tandem mass spectrometry in the environmental and biological monitoring of health care personnel occupationally exposed to cyclophosphamide and ifosfamide. Rapid Commun Mass Spectrom 12:1485-1493

Nygren O, Lundgren C (1997) Determination of platinum in workroom air and in blood and urine from nursing staff attending patients receiving cisplatin chemotherapy. Int Arch Occup Environ Health 70:209-214

Nygren O, Gustavsson B, Strom L, Friberg A (2002) Cisplatin contamination observed on the outside of drug vials. Ann Occup Hyg 46:555-557

Pethran A, Schierl R, Hauff K, Grimm CH, Boos KS, Nowak D (2003) Uptake of antineoplastic agents in pharmacy and hospital personnel. Part I: monitoring of urinary concentrations. Int Arch Occup Environ Health 76:5-10
Raghavan R, Burchett M, Loffredo D, Mulligan JA (2000) Low-level (PPB) determination of cisplatin in cleaning validation (rinse water) samples. II. A high-performance liquid chromatographic method. Drug Dev Ind Pharm 26:429-440

Schmaus G, Schierl R, Funck S (2002) Monitoring surface contamination by antineoplastic drugs using gas chromatography-mass spectrometry and voltammetry. Am J Health Syst Pharm 59:956961

Schreiber C, Radon K, Pethran A, Schierl R, Hauff K, Grimm CH, Boos KS, Nowak D (2003) Uptake of antineoplastic agents in pharmacy personnel. Part II: study of work-related risk factors. Int Arch Occup Environ Health 76:11-16

Sessink PJ, Van de Kerkhof MC, Anzion RB, Noordhoek J, Bos RP (1994) Environmental contamination and assessment of exposure to antineoplastic agents by determination of cyclophosphamide in urine of exposed pharmacy technicians: is skin absorption an important exposure route? Arch Environ Health 49:165-169

Turci R, Sottani C, Ronchi A, Minoia C (2002) Biological monitoring of hospital personnel occupationally exposed to antineoplastic agents. Toxicol Lett 134:57-64

Turci R, Sottani C, Spagnoli G, Minoia C (2003) Biological and environmental monitoring of hospital personnel exposed to antineoplastic agents: a review of analytical methods. J Chromatogr B Analyt Technol Biomed Life Sci 789:169-209

Zeedijk M, Greijdanus B, Steenstra FB, Uges DRA (2005) Monitoring of cytostatics on the hospital ward: measuring surface contamination of four different cytostatic drugs from one wipe sample. Eur J Hosp Pharm Sci 11:18-22

Ziegler E, Mason HJ, Baxter PJ (2002) Occupational exposure to cytotoxic drugs in two UK oncology wards. Occup Environ Med 59:608-612 